Manuscript No. : EFM-D-05-0005

\title{
Treatment of residual stress in failure assessment procedure
}

\author{
Hyeong-Yeon Lee ${ }^{a}$, Farid R. Biglari ${ }^{b}$, Robert Wimpory ${ }^{c}$, Kamran M. Nikbin $^{d *}$ \\ ${ }^{a}$ Mechanical Engineering Division, Korea Atomic Energy Research Institute Dukjindong 150 Yuseong 305-606, \\ Daejeon, South Korea. \\ ${ }^{b}$ Department of Mechanical Engineering, Amirkabir University of Technology, Hafez Avenue, Tehran, Iran. \\ ${ }^{c}$ Hahn-Meitner Institut. Glienicker Strasse 100 D-14109 Berlin Germany \\ ${ }^{d}$ Department of Mechanical Engineering, Imperial College London, South Kensington Campus, London, SW7 2 AZ \\ United Kingdom
}

\begin{abstract}
The effect of residual stress on component failure has been investigated using the distributions from current failure assessment procedures, and a residual stress profile simple to apply with less conservatism has been proposed for the weld geometries of T-plate and tubular T-joint. The Stress intensity factors (SIFs) in the two weld geometries under various types of loads have been calculated using the Green's function method. The Green's functions were determined not only for the T-plate but also for the tubular T-joint with the built-in ends. The use of a linear (bending) stress profile, derived from an analysis of measured residual stress distributions in T-plate and tubular T-joints, has been examined. The profile was validated with experimentally measured residual stress distributions in two materials, a high strength and medium strength ferritic steel and two geometries, a T-plate joint and a tubular T-joint for crack lengths up to half the plate or pipe thickness. Whereas the recommended residual stress distributions are geometry and material specific, it is shown that a simplified linear bending profile provides a possible guideline, applicable to a range of materials and geometries, where detailed information on weld procedures or residual stress profiles are unavailable.
\end{abstract}

Keywords Residual stress, Green's function, Stress intensity factors, T-plate, Tubular T-joint

\section{Introduction}

Residual stress may be classified as stresses that exist in a component after all external forces, including dead weight and thermal gradients, have been removed. When components are joined together by fusion welding, due to the high temperature gradients and plastic deformation in the vicinity of the weld, residual stress fields are invariably set up in the welded joint. It is important that such stresses are accounted for in safety assessment procedures such as the British R6[1] and BS7910[2]. This can be done only when detailed information on the

\footnotetext{
${ }^{*}$ Corresponding author. E-mail : k.nikbin@imperial.ac.uk.
} 
residual stress distribution in the component is known. Since this information is often not directly available, compendia with recommended upper-bound residual stress profiles for use in analyses are included in R6 and BS7910.

In this study, stress intensity factors in welded T-plate and tubular T-joint using measured residual stress distributions and those recommended in assessment procedures are presented. Residual stress distributions have been measured along the thickness direction from the weld toe, where cracks are often found to initiate. The neutron diffraction method was used and stresses were measured along the thickness direction. A medium strength steel (BS EN 10025 Grade S355[3,4]) and a high strength steel (designated SE702, equivalent to the A517 Grade Q steel) have been examined for the T-plate. The former has yield strength of $348 \mathrm{MPa}$ and the latter has yield strength of 700 MPa. The material of the tubular T-joint is designated BS7191 Grade 355 steel, which is equivalent to the BS EN 10025 Grade S355 plate[5]. A linear bending stress distribution was determined which could represent both distributions despite the difference in weld geometry, material and welding variables considered in this study.

The linear elastic stress intensity factors (SIFs) have been determined using the Green's function method(GFM) and the GFs(Green's functions) were determined using finite element method. In general, the weight function method(WFM) is widely used especially for cracked bodies with simple geometries. The advantage of GFM and WFM is that it enables the calculation of the SIFs in a loading-independent way because they depend only on the geometry and boundary conditions, and independent of the applied load [6]. In the meantime the defect of the WFM is that the weight functions (WFs) should be determined prior to actual calculation of the SIFs, which is in general not possible for a structure although some for simple geometries are available in the literature. The WFs for T-plate welded joints were derived in approximate way using composition method [7,8]. In addition, Wang and Lambert [6] used the T-plate joints with built-in ends model to calculate the SIFs for tubular T-joint approximately. Still there is no GFM or WFM applicable to a general structure. In this study, the GFM has been developed for the T-plate and tubular T-joint numerically, which is simple to apply in determination of the SIFs, and applicable to a tubular T-joint with built-in ends.

The results were compared with the SIFs obtained using the stress distributions recommended in the assessment procedures R6 and BS7910. It should be pointed out that the validity range of yield strength, thickness and electrical heat input for welded joints in R6 is somewhat restricted and some of the distributions presented are outside these limits. 
In this work a new residual stress distribution is examined which is less restrictive but has lower conservatism when compared with the analysis results from the measured data and the distributions of R6 and BS7910. The profile is applicable to different geometries of T-plate and tubular T-joints as well as different steels (Grade S355 and Grade SE702).

\section{Material specifications and weld details}

Two geometries of welded T-plate and tubular T-joint were examined in this work. The T-plate specimens were fabricated with high strength ferritic steel SE702 and medium strength low carbon ferritic steel, BS EN 10025 S355. The tubular T-joint was manufactured from the BS 7191 Grade 355 EMZ[5]. The specific material properties for the steels are provided in Table 1[9].

Table 1- Specific uniaxial tensile properties

\begin{tabular}{|c|c|c|c|}
\hline Material & $\sigma_{\mathrm{y}}(\mathrm{MPa})$ & $\sigma_{\mathrm{u}}(\mathrm{MPa})$ & $E(\mathrm{GPa})$ \\
\hline $\begin{array}{cc}\text { BS } & \text { EN } 10025 \text { Grade } \\
& \text { S355 }\end{array}$ & 348 & 515 & 212 \\
\hline SE702 & 700 & $790-940$ & 205 \\
\hline BS 7191 Grade 355 EMZ & 355 & $460-620$ & - \\
\hline
\end{tabular}

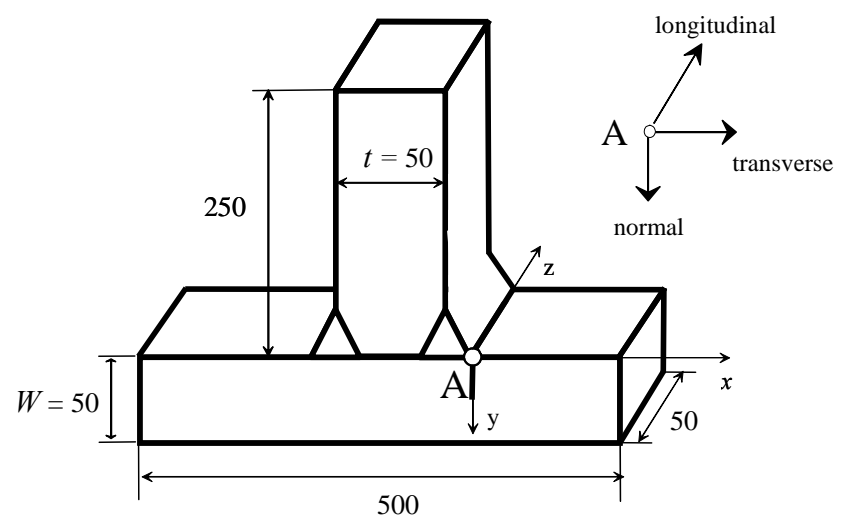

(a) T-plate geometry (SE702)

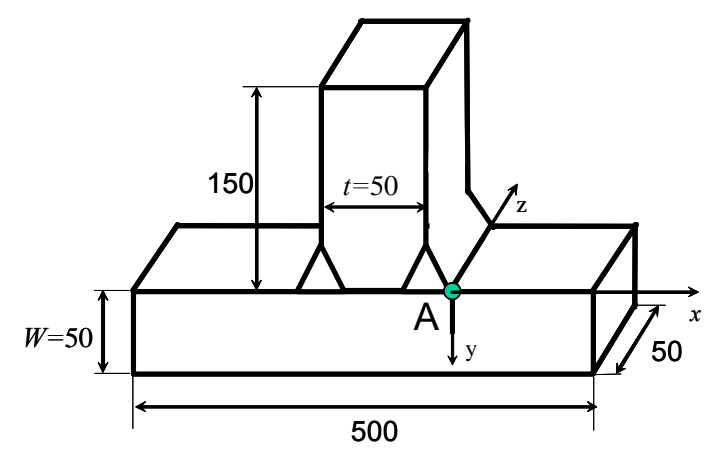

(b) T-palate geometry (Grade S355) 

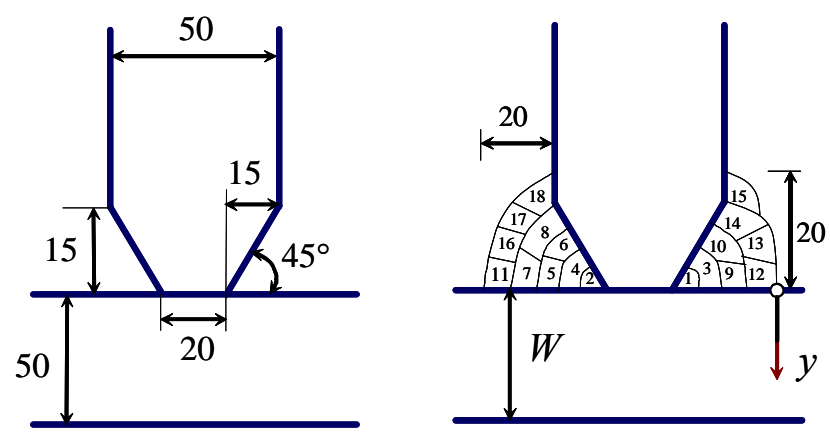

(c) Weld Dimensions and weld sequence (SE702 \& Grade S355)

Fig. 1. Geometry of T-plate and weld, all dimensions in mm (not to scale)

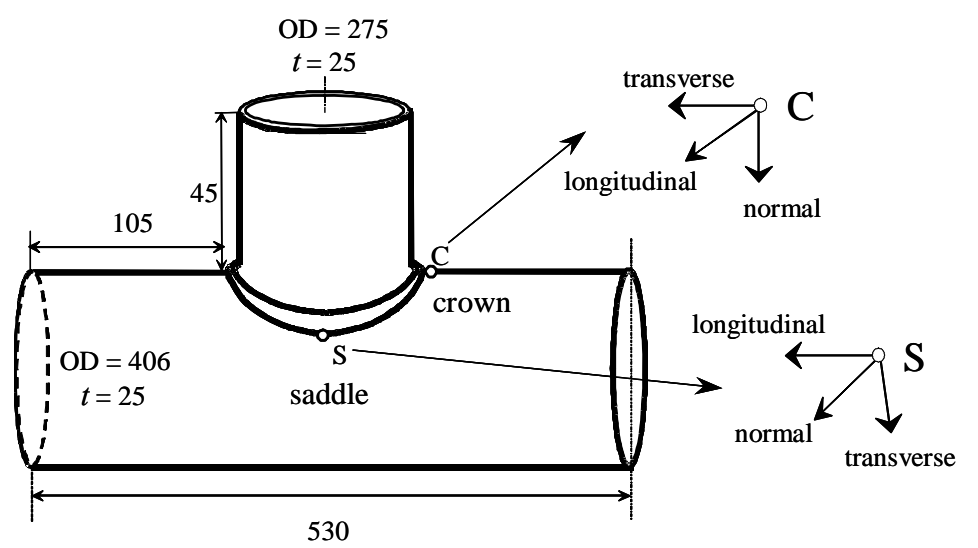

(a) Tubular T-joint

(b)

weld

sequence

Fig. 2. Geometry of tubular T-joint and weld, all dimensions in mm (not to scale)

Manual metal arc (MMA) welding was performed to manufacture the T-plate and tubular T-joint samples. Details of the geometry of the welded T-plate(SE702 and S355) and Tubular T-joint are provided in Fig. 1 and Fig. 2, respectively, and weld sequences are also shown. The weld procedures for the two weld geometries are described in Table 2. In this study the T-plate was globally restrained during welding, while the tubular T-joint was not. The use of restraints during the welding has a strong effect on the peak residual stress magnitude [9]. 
Table 2- Weld parameters

\begin{tabular}{c|cccccc}
\hline Material & Weld type & Restraint & $\begin{array}{c}\text { Weld } \\
\text { pass }\end{array}$ & $\begin{array}{c}\text { Current } \\
(\mathrm{A})\end{array}$ & $\begin{array}{c}\text { Voltage } \\
(\mathrm{V})\end{array}$ & $\begin{array}{c}\text { Heat Input } \\
(\mathrm{kJ} / \mathrm{mm})\end{array}$ \\
\hline Grade S355 (T-plate) & T-butt & Yes & 18 & $170-240$ & $21-23$ & $2.0-2.5$ \\
SE702 (T-plate) & T-butt & Yes & 30 & $500-560$ & $30-31$ & 3.6 \\
Grade 355 (Tubular T) & Pipe T-butt & No & 19 & 160 & 22 & $1.0-2.0$ \\
\hline
\end{tabular}

\section{Residual stress distributions}

Neutron diffraction measurements were carried out to measure the residual stresses along a line (the $y$-axis in Fig. 1(a) \& 1(b)) at the weld toe (point A in Fig. 1(a) \& 1(b)). The three normal stress components are designated normal, transverse and longitudinal as indicated in the inset to Fig. 1(a). The measured data for the T-plate [10] are shown in Fig. 3. These data for the T-plate were obtained at the Institut Laue-Langevin(ILL), Grenoble, France using the monochromatic neutron source, while data for tubular T-joint were obtained at the ISIS neutron facility at the Rutherford Appleton Laboratory, UK. The experimental error bars indicated in the figure are due to the uncertainty in locating the diffraction angle, which is typically \pm 0.01 degrees, which converts to an uncertainty in stress of approx. $\pm 50 \mathrm{MPa}$.

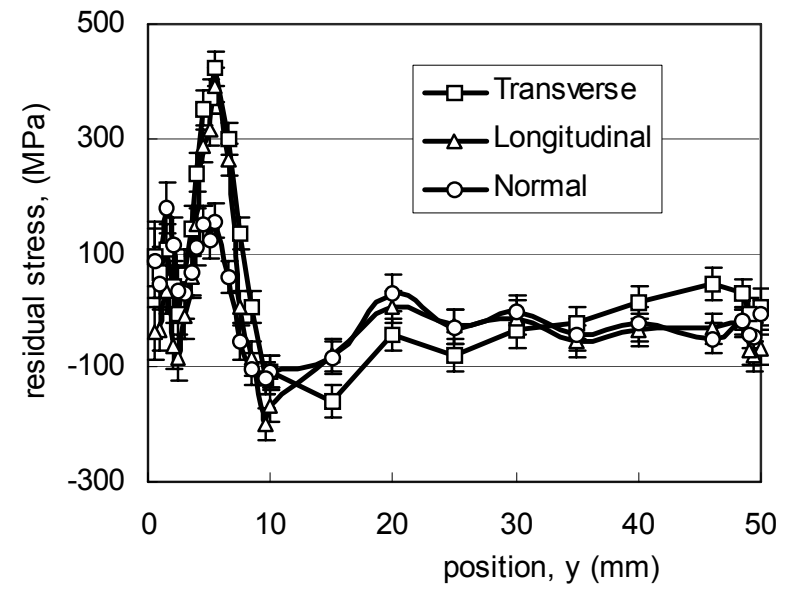

(a) Stress in MPa

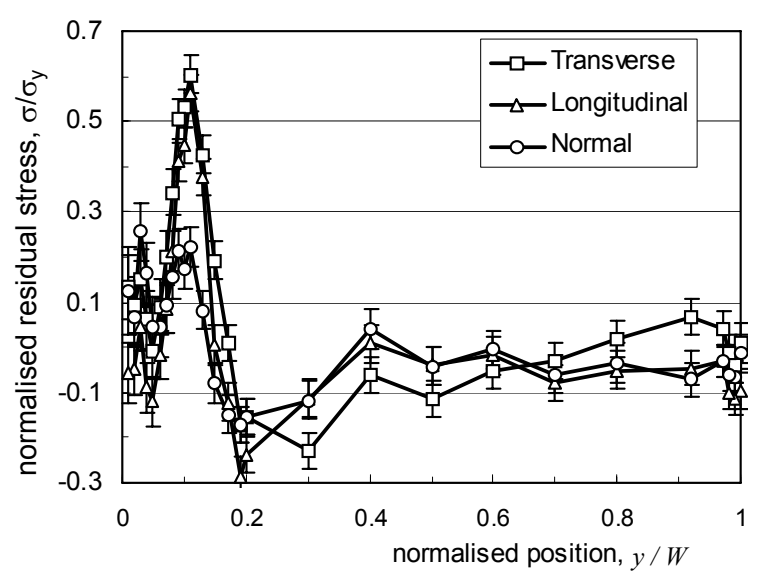

(b) Normalised stress

Fig. 3. Residual stress distributions for the high strength steel T-plate, Grade SE702 ([10])

The method of measuring stresses at a pulsed neutron source are fundamentally different to those used at the reactor and therefore is accepted that there will be variations and differences in measurement methods and 
techniques for data reduction and analysis in deriving residual stresses using different sources. These factors add further to the uncertainties and differences found in the residual stress values of the same component. The present paper considers only a sensitivity analysis due to the variabilities using a simplified linear profile of the residual stress measurements in terms of SIF values which does not need consider the reasons for the different experimental and analysis techniques.

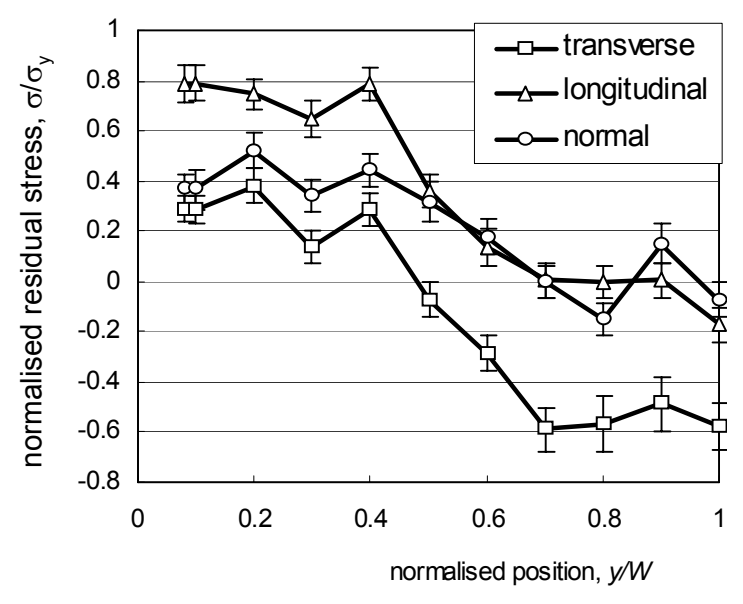

(a) crown

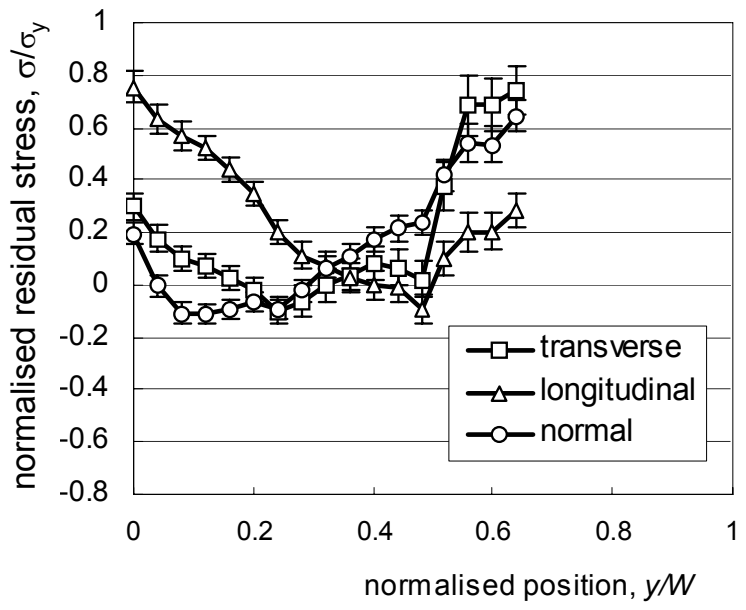

(b) saddle

Fig. 4. Residual stress distributions for tubular T-joints

The measured data for the tubular T-joint at the crown and saddle point, as illustrated in Fig. 2, are shown in Fig. 4. Data for the saddle point are available only up to the normalized position $(y / W)$ of 0.64 . For distances deeper than this, it was impossible to determine the strains with sufficient accuracy due to excessively long neutron path length. The data in Fig. 4 were obtained using the ISIS neutron source at the Rutherford Appleton Laboratory, UK (the data at the crown shown in Fig. 4(a) were carried out using the ENGIN instrument, the data at the saddle shown in Fig. 4(b) were obtained using ENGIN-X, the new neutron facility at ISIS, running since June 2003). It is seen in Fig. 4 that the transverse residual stress distributions, which are of interest in this work dealing with mode I fracture, are quite different at the crown and saddle. The maximum residual stress was found to be near the surface at the crown while it was near mid-thickness at the saddle as shown in Fig. 4(a) and Fig. 4(b). It is also clear in Fig. 4 that the stress levels at the crown are higher than at the saddle but both distributions can be represented by a linear bending type stress distribution up to a normalised position of $0.5(y / W)$, i.e. to the mid-thickness of the measured section. Similar trends to the present tubular T-joint for the transverse residual stress at the saddle have been observed for pipe butt welds as shown in Fig. 5. 
Table 3. Weld details

\begin{tabular}{|c|c|c|c|c|c|}
\hline References & Measurement method & $\begin{array}{l}\text { Plate thickness } \\
(\mathrm{mm})\end{array}$ & $\mathrm{R} / \mathrm{t}$ & $\begin{array}{l}\text { Yield stress } \\
(\mathrm{MPa})\end{array}$ & $\begin{array}{c}\text { Heat input } \\
(\mathrm{KJ} / \mathrm{mm})\end{array}$ \\
\hline $\begin{array}{c}\text { Scaramangas\& PG } \\
{[11]}\end{array}$ & $\begin{array}{l}\text { Sectioning \& hole drilling } \\
\text { \& EDM } \\
\text { Sectioning \& hole drilling }\end{array}$ & 9.1 & 54.96 & 520 & 0.8 \\
\hline Leggatt [12] & & 15.5 & 19.7 & 540 & $0.56-1$ \\
\hline Present (tubular T) & Neutron diffraction & 25 & 11 & $460-620$ & $1-2$ \\
\hline
\end{tabular}

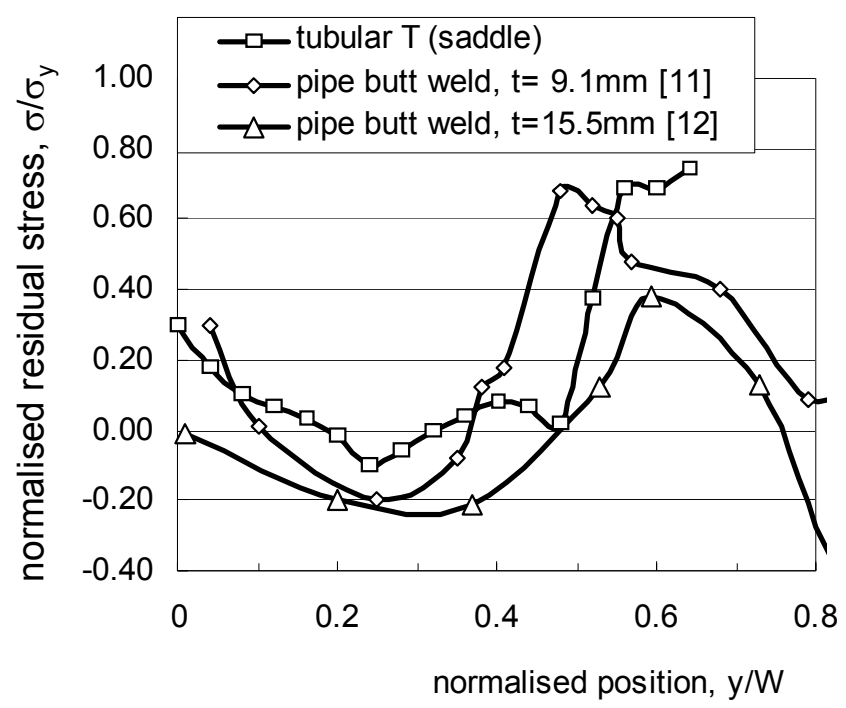

Fig. 5. Comparison of transverse residual stress for tubular T-joint and pipe butt welds

\subsection{Simplified analysis of residual stress data from components}

From the data presented in Fig. 3 and Fig. 4 it can be seen that there is considerable variation in the shape of the residual stress distributions for the different geometries and location. However, the overall magnitudes of the stresses are comparable (when stresses are normalised by yield strength). Fig. 6 shows the individual transverse stresses for the two T-plate tests made of high strength steel SE702 steel and the medium strength steel Grade S355 [3], and the two data sets for the saddle and crown of the tubular T-joint. 


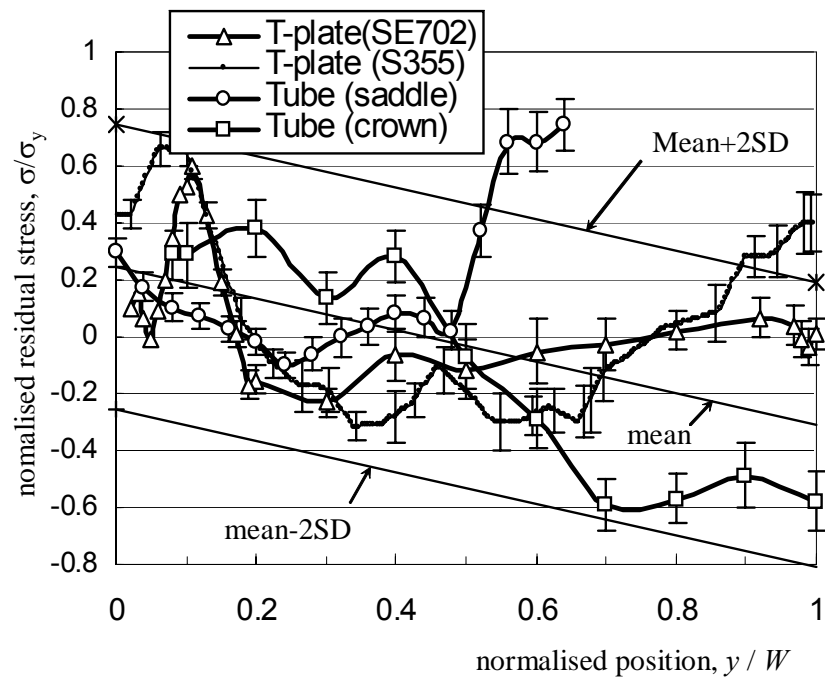

Fig. 6. Transverse residual stress distributions for a range of welded geometries and the statistical mean, upper and lower bounds of the data at $\pm 2 \mathrm{SD}$

Table 4. Analysis of the residual stress data

\begin{tabular}{ccccc}
\hline Geometry & case & $\begin{array}{c}\text { Normalised } \\
\text { stress at } y / W=0\end{array}$ & slope & $\begin{array}{c}\text { Standard Deviation } \\
\text { (SD) }\end{array}$ \\
\hline \multirow{2}{*}{ T-plate } & SE702 & 0.19 & -0.24 & 0.20 \\
& S355 & 0.10 & -0.17 & 0.34 \\
\hline \multirow{2}{*}{ Tubular T } & crown & 0.48 & -1.17 & 0.23 \\
& saddle & -0.07 & 0.79 & 0.25 \\
\hline All specimens & ALL & 0.25 & -0.56 & 0.25 \\
\hline
\end{tabular}

Least square linear fits have been calculated for each of the data sets individually as well as for all the data shown in Fig. 6. This figure also shows the best fit mean values for all the data and the upper/lower bound lines at two standard deviations (2SD). The corresponding values of the mean slopes and standard deviations for the datasets are provided in Table 4. It may be noted that the slope (which is a measure of the magnitude of the linear bending stress) is higher than the value of the stress at $y / W=0$ (which is a measure of the mean (membrane) stress) in all cases. The T-Plate (S355) has the lowest mean slope and the tubular T-joint at the crown has the highest slope. The normalized linear mean line, for all the data, shown in Fig. 6 is given by:

$$
\frac{\sigma}{\sigma_{\mathrm{y}}}=-0.56\left(\frac{y}{W}\right)+0.25
$$

The form of Eq. (1) indicates that the mean curve is composed of a membrane (uniform) stress component of $0.25 \sigma_{y}$ and a bending (linear) stress slope of $-0.56 \sigma_{y}$. The degree of conservatism or otherwise, in estimating the SIF 
for the various geometries, using a linear fit of this type, will be examined in the analysis section. In general the crack length of interest in actual failure assessment is relatively short and well below $y / W=0.5$ of the component witdth. In this work the crack lengths up to half the thickness has therefore been considered allowing the need to apply the stresses on the crack surface to a depth of $y / W=0.5$ using the superposition rule since the stress distributions over the region of $y / W>0.5$ do not influence the SIF values. It should also be noted that the stresses in the region $y / W>0.5$ are usually compressive and will have little effect on SIF values for short cracks. Therefore, the dataset with different patterns of having maximum peak at mid-wall as shown in Fig. 4 (saddle) and Fig. 5 (pipe butt) over the region of $y / W>0.5$ need not be taken into account in this analysis and are assumed to be zero in the model making the profile more conservative.

\subsection{Residual stress distributions from R6 and BS 7910}

\subsubsection{R6 distributions for T-plate}

In the R6 procedure, two approaches for defining residual stress profiles in welded T-plates are provided, depending on the available information about welding conditions. If the welding conditions are known or can be estimated, then residual stress profiles given by the following Eqs. (2) and (3) may be used, which are associated with the size of the plastic zone $\left(r_{\mathrm{o}}\right)$. If the welding conditions are unknown, polynomial functions are provided.

The recommended through-thickness transverse residual stress distribution in the T-plate consists of an upper bound bilinear profile. The peak stress is at the weld toe and equal to the parent material yield stress and reduces linearly to zero at a distance $r_{\mathrm{o}}$ from the weld toe. The distance $r_{\mathrm{o}}$ represents the size of the yielded zone (mm) as recommended by Leggatt[13].

If $r_{\mathrm{o}} \leq W$, where $W$ is the plate thickness (mm), then

$$
r_{o}=\sqrt{\frac{K}{\sigma_{y}} \frac{\eta q}{v}},
$$

where $K$ is a material constant that depends on the coefficients of thermal expansion, Young's modulus, density and specific heat of a material $(\mathrm{Nmm} / \mathrm{J}), \sigma_{\mathrm{y}}$ is yield or $0.2 \%$ proof strength of parent metal, $q$ is arc power, $v$ is weld travel speed, $\eta$ is process efficiency (fraction of arc power entering plate as heat). Typical values of $K$ and $\eta$ for a 
range of materials are provided in the R6 documents. For ferritic steels the values provided are $K=153 \mathrm{Nmm} / \mathrm{J}$ and $\eta=0.8$.

If Eq. (2) results in a plastic zone greater than the base plate width $\left(r_{0}>W\right), r_{0}$ must be recalculated using,

$$
r_{o}=\frac{1.033 K}{\sigma_{y}} \frac{\eta q}{v(W+0.5 t)}
$$

The value of $r_{\mathrm{o}}$ is obtained from Eq. (2) for both T-plate geometries analysed here, giving $r_{\mathrm{o}}=25 \mathrm{~mm}$ for the SE702 and $r_{\mathrm{o}}=27 \mathrm{~mm}$ for the Grade S355 steel. Since these two values are very close, a single R6 curve is plotted in Fig. 7(a) with $r_{\mathrm{o}}=26 \mathrm{~mm}$. If weld information is unavailable then the BS7910 polynomial distribution is used.

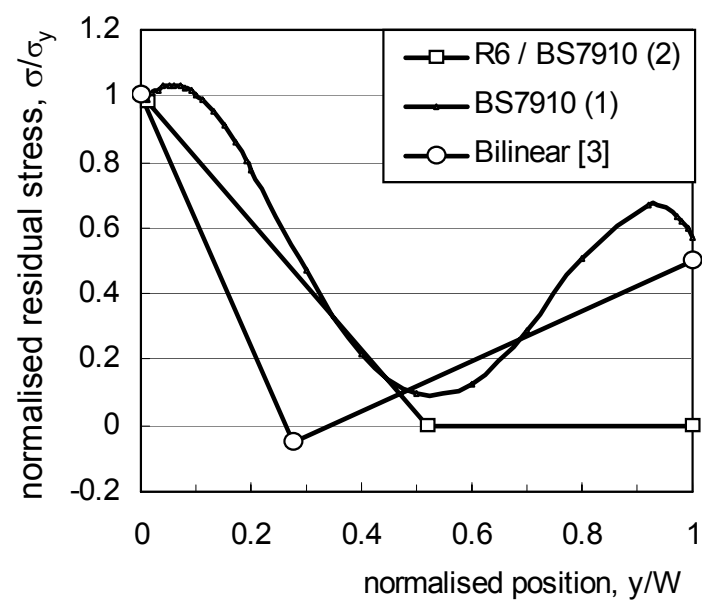

(a)

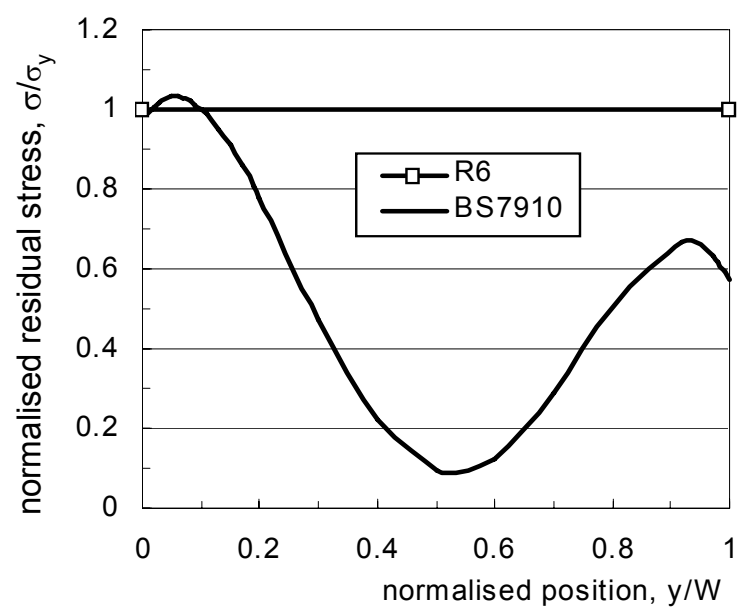

(b)

Fig. 7. Transverse residual stress distributions (a) T-plate (b) Tubular T-joint

\subsubsection{R6 distributions for tubular T-joint}

The tubular T-joint is included in the 'Pipe T-butt weld' part of the R6 procedure. The profiles are generated from geometries where the ratio of the chord thickness ( $W$ in Fig. 2$)$ to the brace thickness $(t$ in Fig. 2) varies from 1.375 to 2 . For cases where $W / t<1.375$, a uniform tensile residual stress is assumed. For cases $W / t>2$, the profiles of the above plate T-butt welds are recommended. For cases $1.375<W / t<2$, the same equation as BS7910 is applied (see below). In the present tubular T-joint with $W / t=1$, the recommended R6 distribution is a uniform stress through the thickness of yield stress magnitude, as shown in Fig. 7(b). 


\subsubsection{BS 7910 distributions for T-plate}

BS7910 provides two transverse residual stress distributions for T-plate joints. The first transverse residual stress distribution is a polynomial function representing an upper bound fit to experimental data and is given by the following Eq. (4). This distribution is here referred to as BS7910 (1).

$$
\sigma_{\text {res }}=\sigma_{y}\left\{0.97+2.3267\left(\frac{y}{W}\right)-24.125\left(\frac{y}{W}\right)^{2}+42.485\left(\frac{y}{W}\right)^{3}-21.087\left(\frac{y}{W}\right)^{4}\right\}
$$

The second distribution follows that in R6, with the distribution dependent on the size of the plastic zone. When the plastic zone size $r_{0}$ calculated by Eq. (2) is less than the base plate thickness, the residual stress is taken to be that of the parent material yield stress level at the weld toe, reducing linearly to zero over the size of the yielded zone as in R6. However, Eq. (3) is not used in BS7910. If Eq. (2) results in a plastic zone greater than the base plate width, the stress is taken to be equal to the yield strength across the whole specimen thickness. This distribution is referred to here as BS 7910 (2).

\subsubsection{BS 7910 distributions for tubular T-joint}

The recommended transverse residual stress profile for the tubular T-joint is the same polynomial function as that provided for T-plate welds (Eq. (4) and the distribution is provided in Fig. 7(b). This polynomial type profile is conservative but less conservative than R6 for the current geometry as shown in Fig. 7(b). It should be noted that for the current geometry BS7910 provides a more conservative residual stress profile than R6 for the T-plate while R6 is more conservative for the tubular T-joint.

\subsubsection{Bilinear distribution}

A bilinear distribution based on residual stress data for a range of T-plate joints in ferritic steels was suggested in reference [3]. This distribution, which has been obtained by shifting a mean bilinear fit to the data by a uniform (membrane) stress of $0.25 \sigma_{y}$, is shown in Fig. 7(a). It may be seen that of the available stress distributions for a Tplate, the polynomial function distribution of BS7910(1) is the most conservative followed by the R6 distribution and then the bilinear distribution. 


\section{Finite Element Analysis}

The finite element (FE) meshes used in this work are illustrated in Fig. 8. The T-plate is assumed symmetric with weld angle of $80^{\circ}$. A crack of length, $a$, is included at the right hand weld toe as shown in Fig. 8(a). A total of 13,540 linear elements and 14,094 nodes was used and the smallest element size is $0.03 \mathrm{~mm}\left(6 \times 10^{-4} \mathrm{~W}\right)$ for the Tplate mesh. The tubular joint is a three dimensional geometry, but here is represented by an axisymmetric, "tube on plate” FE mesh as illustrated in Fig. 8(b). A total of 13,534 linear elements and 14,091 nodes were used and the smallest element size is $0.015 \mathrm{~mm}\left(6 \times 10^{-4} \mathrm{~W}\right)$. All finite element analyses were carried out using the commercial FE software package, ABAQUS 6.3 [14] to determine the Green's functions (see below) to calculate the SIFs. Only transverse residual stresses are considered and the mode I, SIFs have been evaluated.

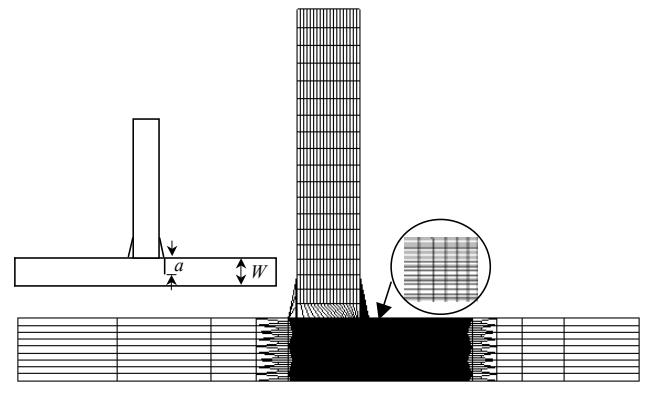

(a)

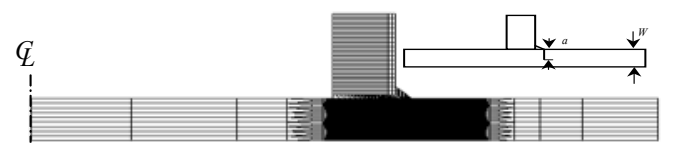

(b)

Fig. 8. Finite Element Meshes (a) T-plate (b) Representation of tubular T-joint

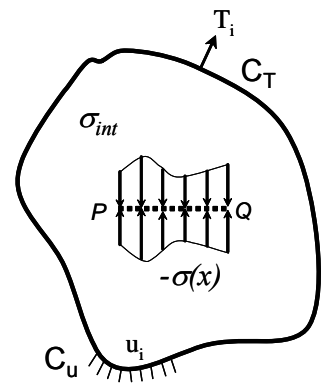

(a)

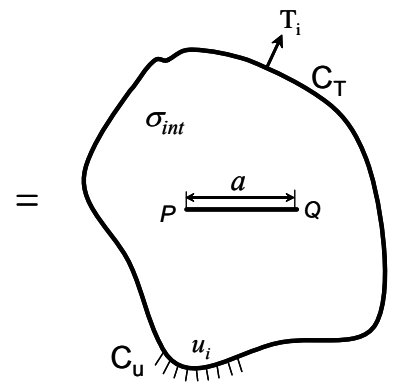

(b)

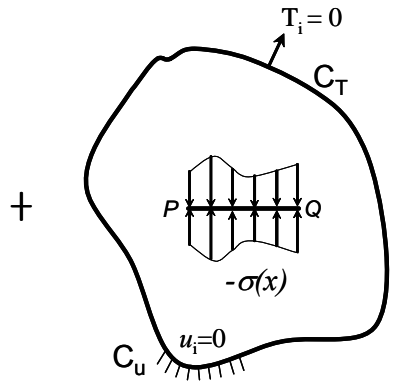

(c)

Fig. 9. Superposition principle for stress intensity factor [15] 


\section{Green's function approach}

\subsection{Superposition principle and Weight function method}

At this point it would be useful to outline the method for evaluating the SIF for the components. The SIFs under various kinds of loads can be calculated using the superposition principle. Consider a crack-free body as shown in Fig. 9(a) subjected to prescribed tractions $T_{i}$ over the boundary $C_{T}$ and to prescribed displacements $U_{i}$ over the boundary $C_{U}$; in addition it may contain a self-equilibrating internal stress system $\sigma_{i n t}$ such as residual stress [15]. Since the problem is linear elastic, Fig. 9(a) can be decomposed as Fig. 9(b) and 9(c). According to the concept of superposition and fracture mechanics, a crack problem under any prescribed load or displacement as well as internal stress can be reduced to a problem with only crack surface stress, or alternatively crack face pressure, $\sigma(\mathrm{x})$ as shown in Fig. 9.

The weight function method (WFM) is widely used especially for cracked bodies with simple geometries. The advantage of WFM is that it enables the calculation of the SIFs in a loading-independent mode since the weight function depends only on the geometry and boundary conditions, and independent of the applied load[6]. The SIF for various applied loads can be determined by integrating the product of the weight function(WF), $m(x, a)$, and the crack surface stress distribution, $\sigma(x)$ as in Eq. (5).

$$
K=\int_{0}^{a} \sigma(x) m(x, a) \mathrm{d} x
$$

The weakness of the WFM is that the WFs should be determined prior to actual calculation of the SIFs, which is generally not possible so far for structures. The WFs for T-plate welded joints were previously derived in approximate way using composition method $[7,8]$ as shown in Fig. 10 since the WFs for the T-plate with finite dimensions are not available. In addition, Wang \& Lambert derived the WF for tubular T-joint and they determined the WF for problem with built-in end as shown in Fig. 11[6]. The T-plate with built-in ends is a statically indeterminate problem and the WF approach of these structures [6] is quite complicated since procedure such as taking the load shedding (change of reaction force) need to be taken into account. 


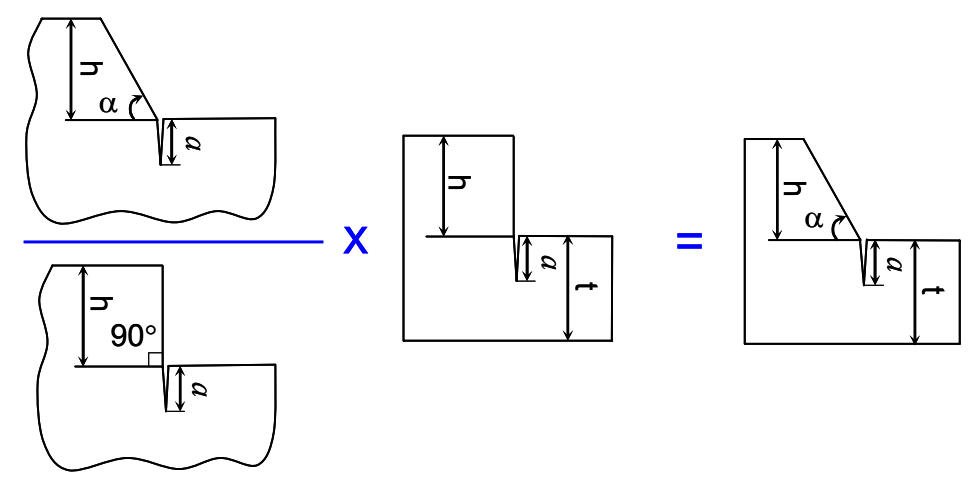

Fig. 10. Composition method to determine a weight function for T-plate

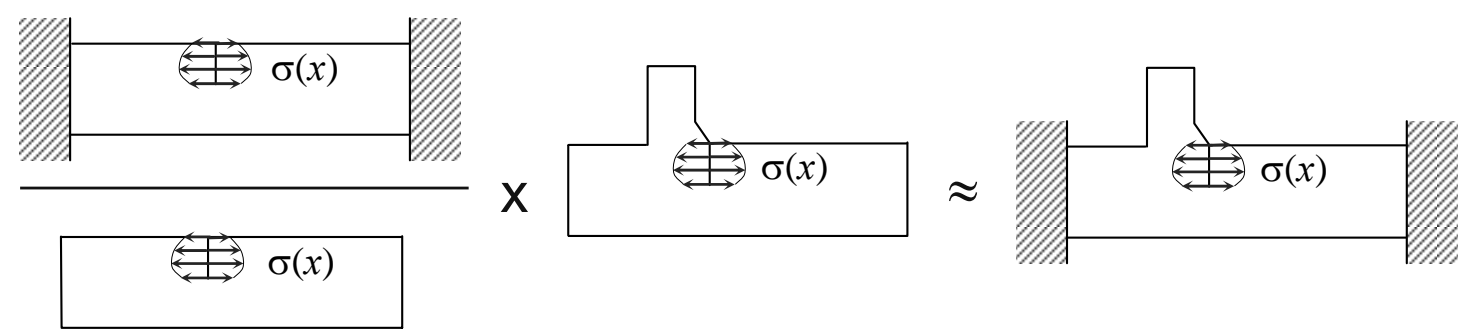

Fig. 11. Composition method for surface crack in T-plate with built-in ends

\subsection{Green's function method}

In this study, the Green's function method (GFM) has been developed for the T-plate and tubular T-joint which is simple to apply in the determination of the SIFs. The Green's function (GF), $G(x)$ is calculated under the load case in which the cracked body is loaded at its surfaces by two pairs of symmetric, normal point forces as shown in Fig. 12. Then the SIF can be determined by the Eq. (6)

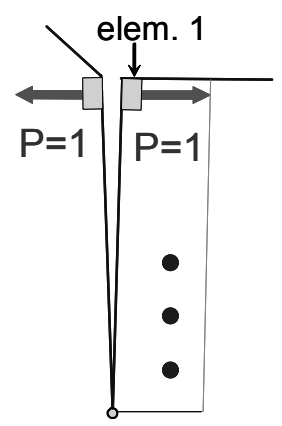

crack tip

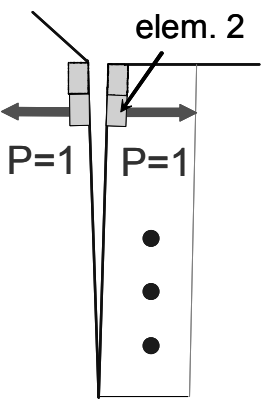

Fig. 12. Loading unit force on the crack surface 


$$
\begin{aligned}
& K=\frac{P}{\sqrt{\pi a}} G\left(a, \frac{x}{a}\right) \\
& G\left(a, \frac{x}{a}\right)=\sqrt{\frac{1-(a / x)}{2}} \sum_{i=1}^{n} \beta_{i}(a) \cdot\left(1-\frac{x}{a}\right)^{i-2}
\end{aligned}
$$

where $G(a, x / a)$ is the GF, $a$ is crack length, $x$ is location on the crack surface and $\beta_{\mathrm{i}}$ is the coefficient of the Green's function. The GF coefficients of $G(a, x / a)$ are available only for simple crack geometries in the literature[15].

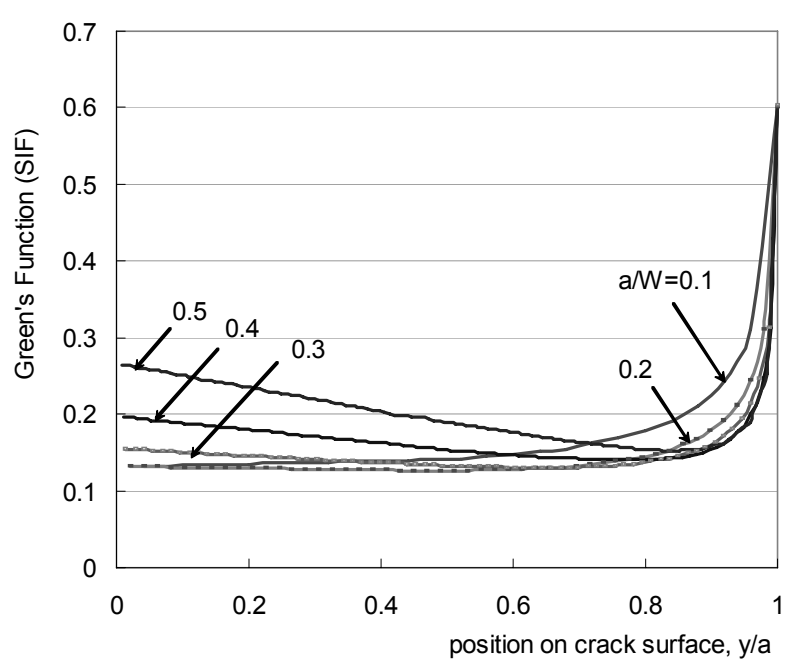

(a) T-plate

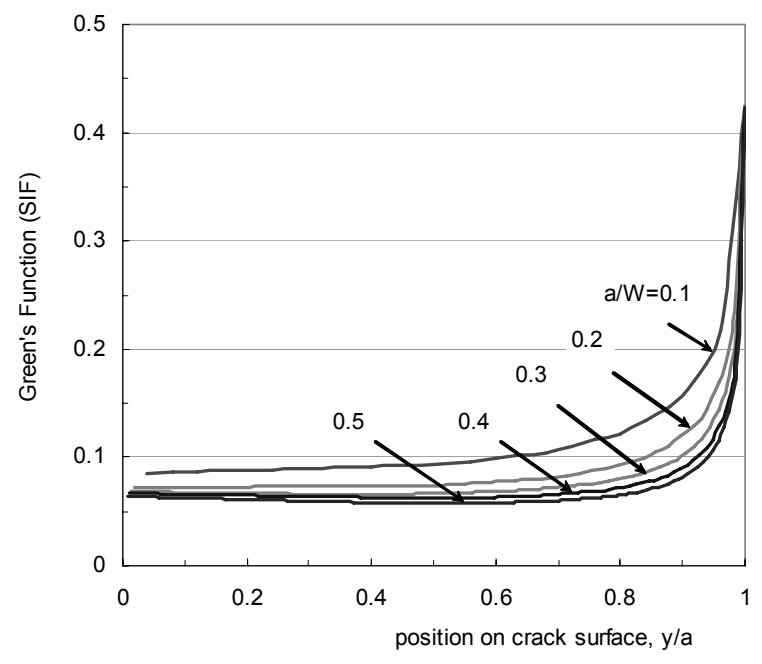

(b) Tubular T-joint

Fig. 13. Green’s Function for welded components

For a specific crack length, the GFs can be determined analytically or numerically for simple crack geometries. However, it is not generally possible to determine the GF for a complicated structure. In this study the GFs for a specific crack length has been fitted using the GFs determined at some selected locations on the crack surface. The GFs for the present T-plate and tubular T-joint are shown in Fig. 13, which shows that the GFs for tubular T-joint are monotonically decreasing while that for T-plate is not. When five locations on the crack surface were selected for the T-plate, the difference between the present Green's function approach and FEM was $2.5 \%$ and when 10 locations were selected the difference was less than $1 \%$. Although it needs to determine the GFs as many as 10 points to obtain an accurate SIF values, this approach is very powerful especially for a complicated structures where neither WFs nor GFs are available so that WFM and GFM are not applicable. 
The determination procedure of the GFs at the locations of the crack surface is very simple. The GF for a specific location is the SIF due to a pair of unit point force and is easily determined using FEM. It is important to note that this numerical approach to determine the GF is applicable even to the statically indeterminate problem (built-in case for tubular T-joint) as well as T-plate problem. The GFs determined for the tubular T-joint with builtin end (at right end in Fig. 8(b)) are shown in Fig. 13(b).

So far a general method to determine the Green's function or weight function in closed-form solution type for a structure is not available. In this study the GFs were determined numerically over several locations on the crack surface and fitted to determine a GF for a specific crack length. The validation of the present approach for tubular Tjoint (statically indeterminate) as well as T-plate (statically determinate) is as follows.

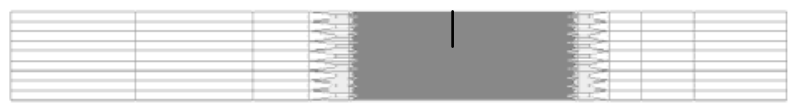

(a) smooth plate with edge crack

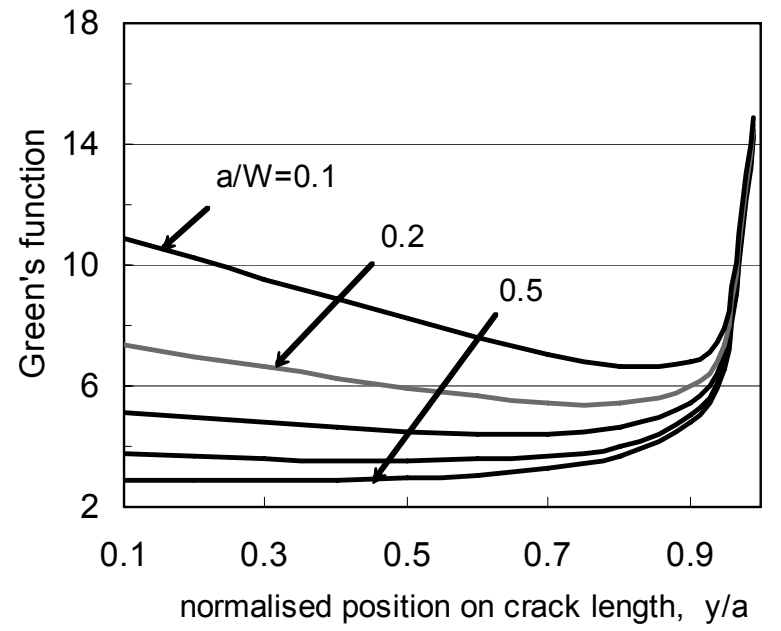

(b) Green's function for edge cracks

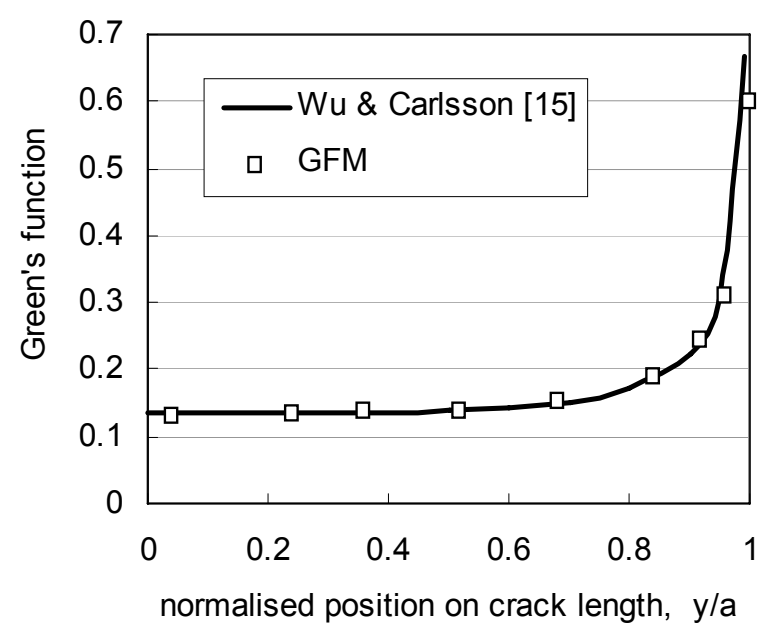

(c) Comparison of the results by GFM and closed-form solution[15]

Fig. 14. Application of the Green's function method for smooth plate 


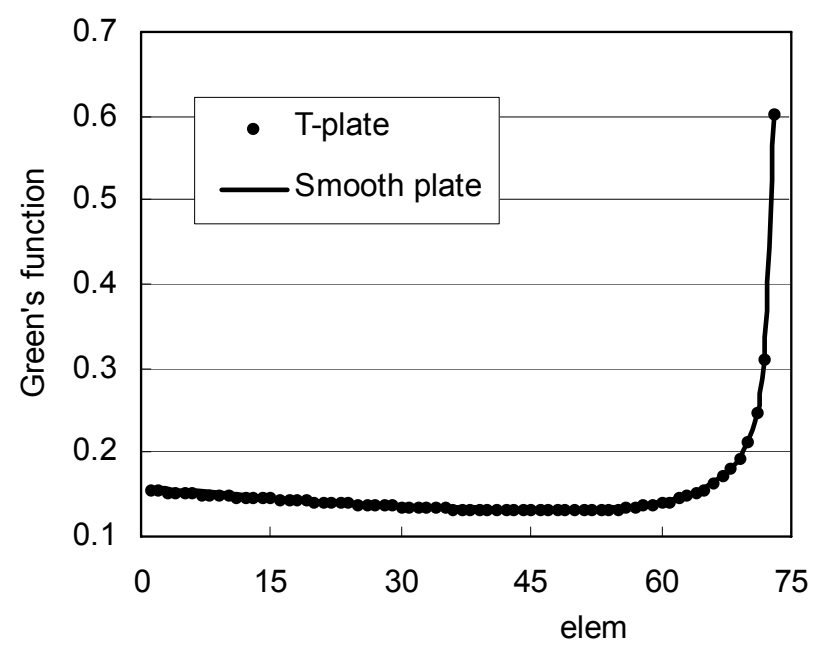

Fig. 15. Comparison of the Green’s function for T-plate \& smooth plate

The cracked body of smooth plate without upper attachment in T-plate is similar to single edge cracked body as shown in Fig. 14(a). The GF solution [15] of the single edge crack was applied to the present smooth plate and was compared with the results by the finite element analysis. The analysis results showed that the present GFM is in good agreement with the closed form solution [15] as shown in Fig. 14(c). In addition, it is interesting to note that the GF of T-plate is very close to that of smooth plate as shown in Fig. 15. That is because the GF is determined only by crack surface load and no load is applied on the upper attachment of the T-plate.

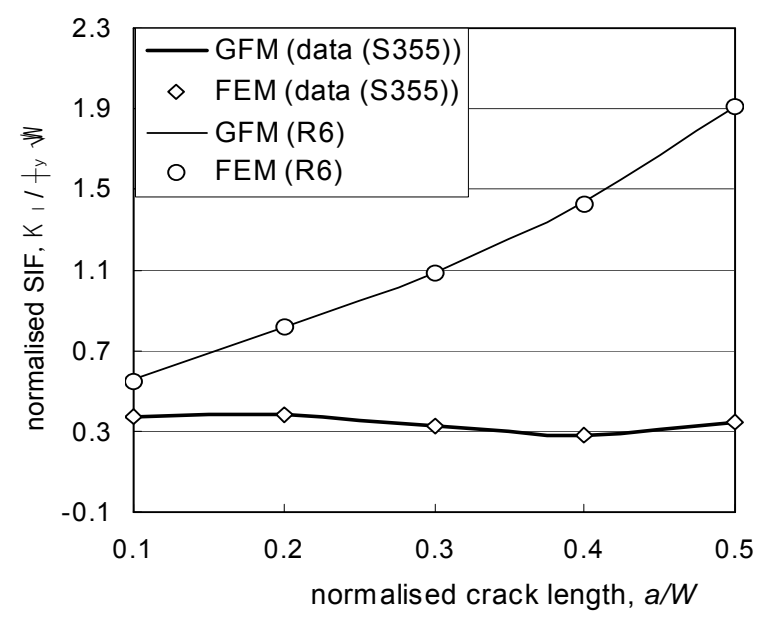

(a) T-plate

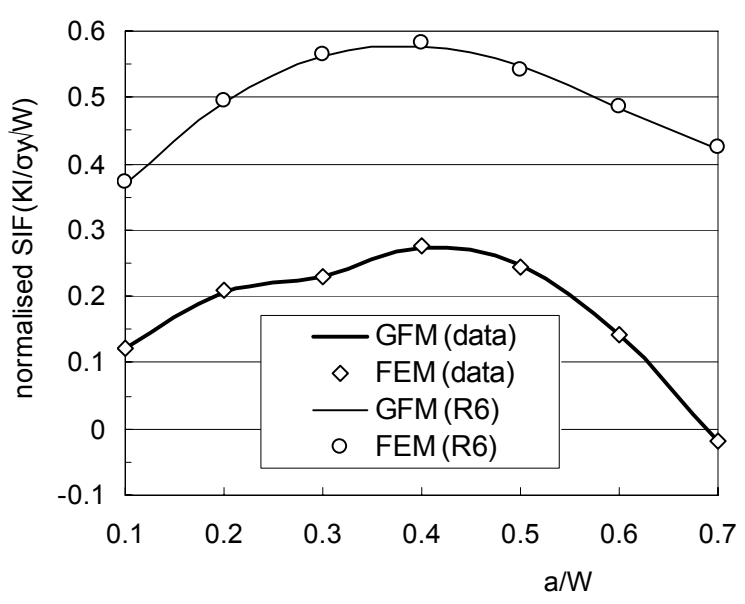

(b) Tubular T-joint

Fig. 16. Comparison of the SIF results by Green’s function method and finite element method 
The SIFs for various residual stress profiles can be determined using the present GFM. The SIFs using the GFM for the measured residual stresses and R6 profile for S355 steel are shown in Fig. 16. The behaviour of present approach using the GFs for the T-plate(statically determinate) and tubular T-joint with built-in end(statically indeterminate) shows that present GFM is in good agreement with the results by finite element analysis.

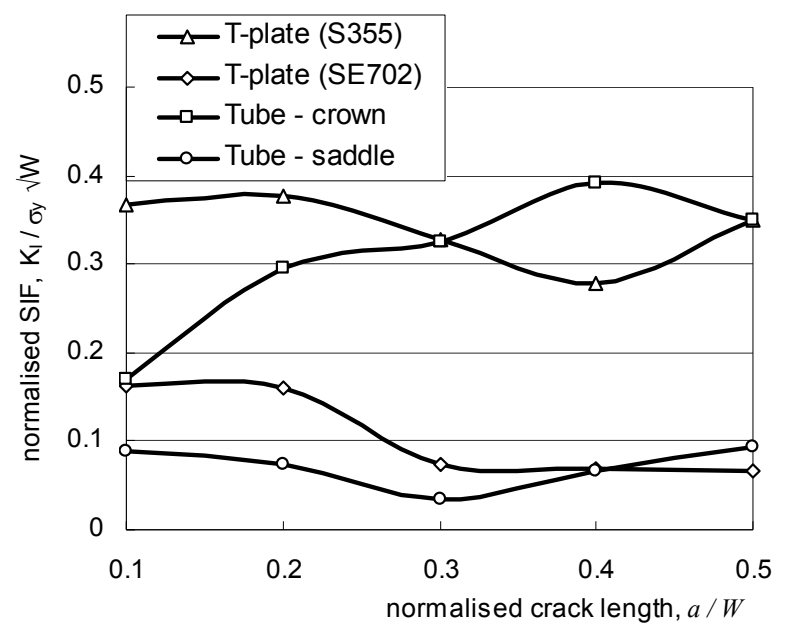

(a) normalised SIFs

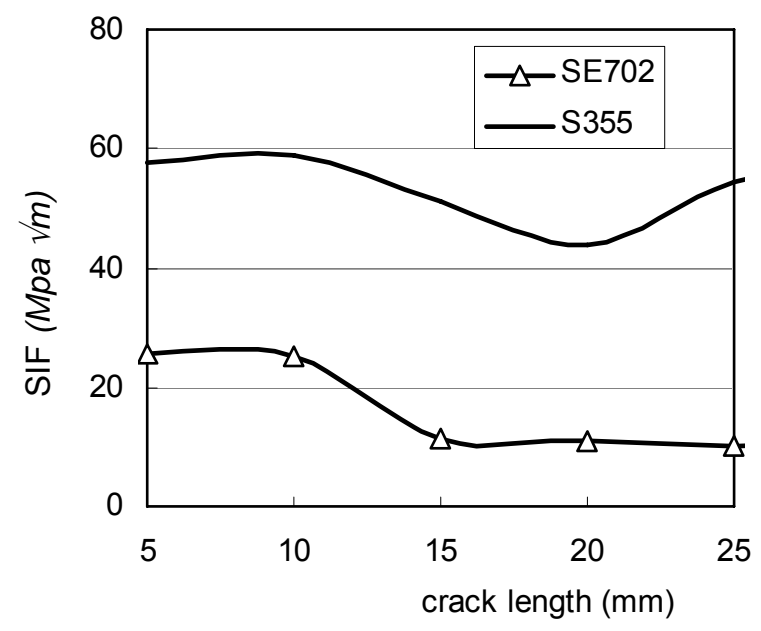

(b) SIFs of two materials for T-plate

Fig. 17. Stress intensity factors of measured data for T-plate and tubular T-joint

\section{Results of the analysis}

\subsection{Stress intensity factors for measured data}

The normalised stress intensity factors for the four sets of measured transverse residual stress shown in Fig. 6 data were calculated using the GFM. The results are given in Fig. 17(a). It is clear that given the variation in the residual stress distribution, the SIF values will also vary for the different geometries. The normalised SIFs of the Tplate for SE702 and Grade S355 are similar in shape with the result for S355 about two times higher than those of SE702 but the normalized SIFs for the tubular T-joint at the crown and saddle point are quite different. The transverse residual stress at the crown is positive over most of the region $0<y / W<0.5$, as seen in Fig. 4(a), which explains the reason why the calculated SIF for crown point is the highest among the four cases examined. The transverse residual stress over the region $0 \leq y / W \leq 0.5$ is lowest at the saddle, as shown in Fig. 4, and, correspondingly, it gives the lowest SIF values. The SIFs of the two materials for T-plate are shown in Fig. 17(b), 
which shows similar trend to Fig. 17(a). The SIFs for SE702 are considerably lower than the fracture toughness $\left(K_{I C} \approx 240 \mathrm{MPa} \sqrt{\mathrm{m}}[10]\right)$ and those for S355 are also lower than the toughness $\left(K_{I C}\right.$ data lies between 100 and 150 $\mathrm{MPa} \sqrt{\mathrm{m}}[9])$. It is shown that the residual stress should have a significant effect on fracture behaviour for short cracks as shown in Fig. 17(b) when comparing to the toughness values. It is also shown that the contribution of residual stress to fracture for high strength steel of SE702 would be larger than the case of S355.

\subsection{Simplificaiton of the 'Case Specific' residual stress profile for the T-Plate and Tubular T-Joint components}

As shown in Fig. 7 the available residual stress profiles are 'case specific' and can be very conservative as upper bounds of measurement data have been used to directly fit them. In this section a sensitivity analysis is carried out to identify the effects that different linear simplified residual stress distribution for the T-plate and tubular T-joint have on the SIF values based on available experimental residual stress profiles.

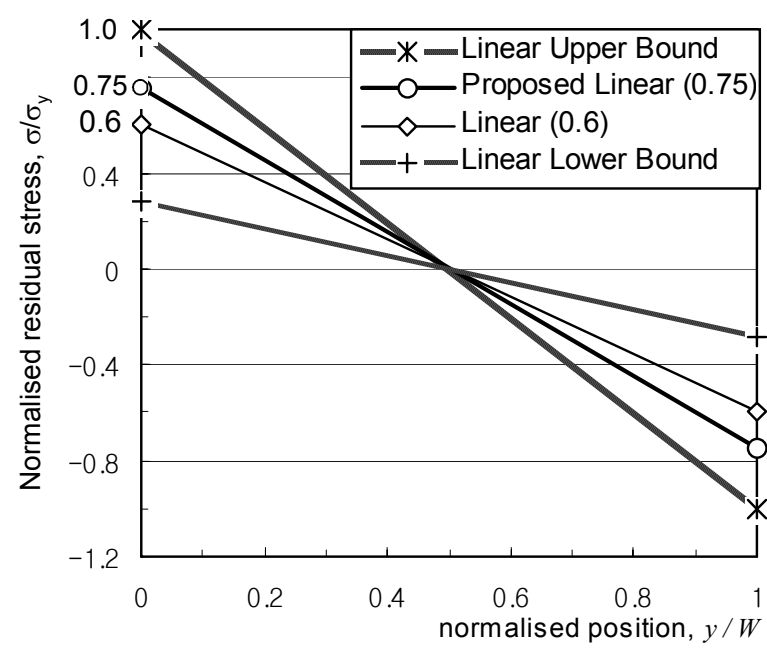

(a)

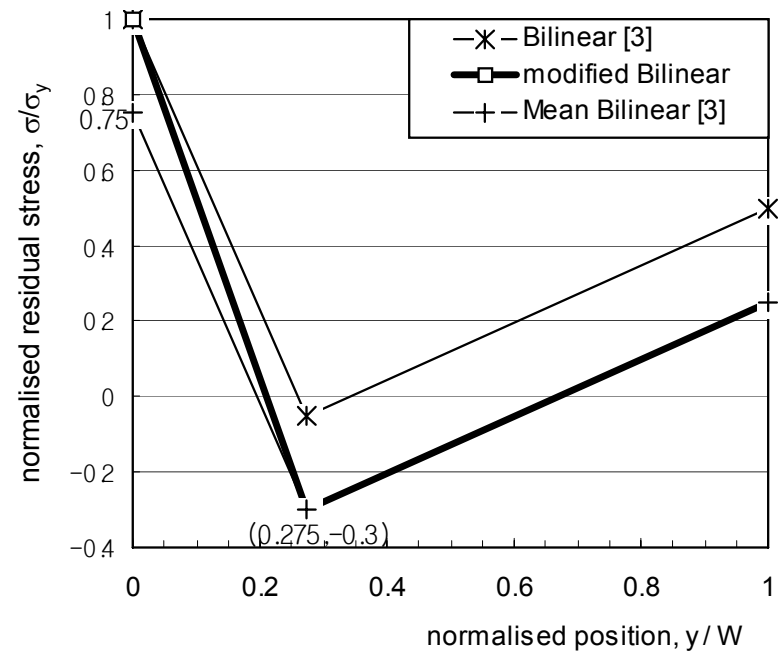

(b)

Fig. 18. Proposed residual stress profiles (a) linear profiles (b) bilinear profiles

The simplification of the stress profiles is proposed by considering various linear bending stress distributions as shown in Fig. 18(a) based on the linear regression line (Eq. (1) and Fig. 6). Rather than adding a uniform (membrane) stress to the mean distribution, as was done previously in [3], the slope of the mean line is changed while keeping the 'pivot point' value at $y / W=0.5$ fixed. Eq. (1) gives $\sigma / \sigma_{\mathrm{y}}=-0.03$ at $y / W=0.5$. For convenience, this value has been set to zero and a modified 'mean' linear fit has been used in what follows, 


$$
\frac{\sigma}{\sigma_{\mathrm{y}}}=-0.56\left(\frac{y}{W}\right)+0.28
$$

Variations to the mean are examined by allowing the surface stress (at $y / W=0$ ) to range from yield stress $\sigma / \sigma_{y}$ $=1$ (the R6 value) to $\sigma / \sigma_{y}=0.28$ (lower bound). A surface stress value of $0.75 \sigma_{y}$ (as the point $+2 \mathrm{SD}$ from the mean slope, with a fixed pivot point) and $0.6 \sigma_{y}$ are chosen within this range. The use of these values effectively spans the distributions in Table 4. In this study since crack lengths of up to $a / W=0.5$ have been considered the compressive residual stress over the region of $a / W>0.5$ in Fig. 18(a) are not relevant in the SIF calculation based on the superposition principle. The present profile is comparable with the 'mean+bend' profile which combines the adjustment of membrane as well as bending term[16].

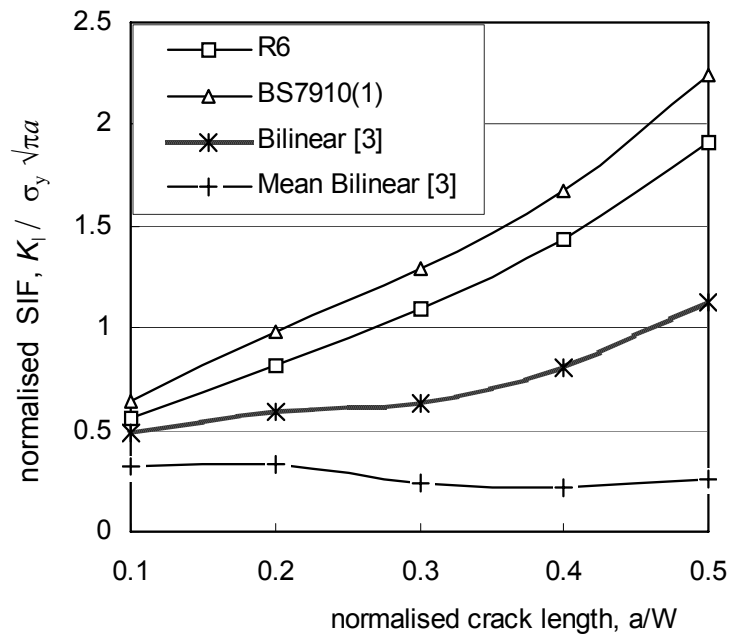

(a)

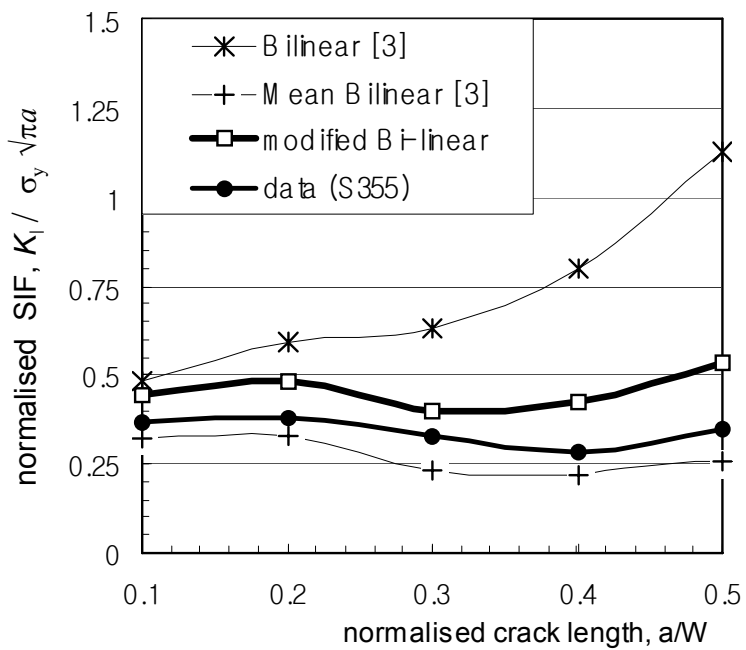

(b)

Fig. 19. The SIFS for T-plate (a) Existing distributions (b) Bilinear distributions compared with data

In addition in this study based on the sensitivity analysis carried out above the bilinear distribution developed previously[3] for T-plates as shown in Fig, 18(b) has also been examined in the same manner and a sensitivity analysis for the SIF values have been carried out. Thus, as shown in Fig. 18(b) three different bilinear curves can be analysed, identified as bilinear, modified bilinear and mean bilinear. These profiles have been applied as transverse residual stress distribution to the T-plate and tubular T-joint in order to perform a sensitivity analysis of the SIF values. 


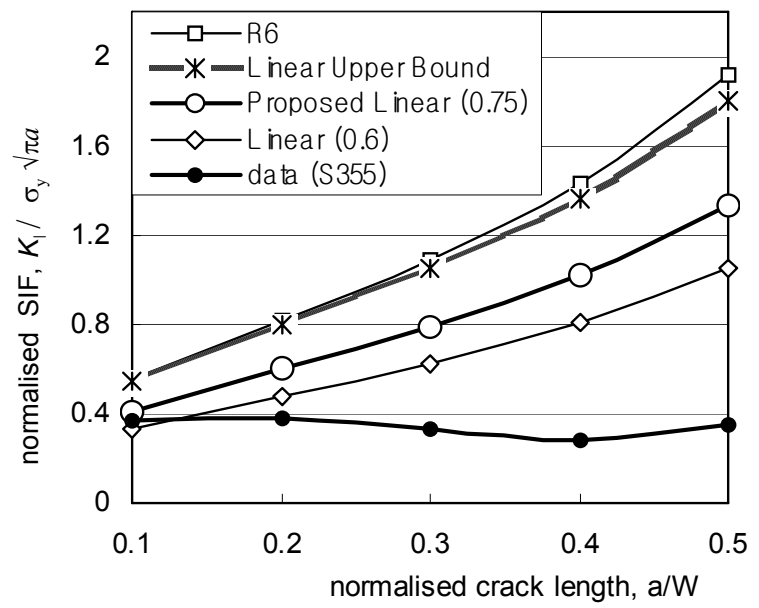

Fig. 20. Comparison with the SIFs for T-plate for S355 steel and those obtained using the proposed residual stresses profiles

\subsection{Stress Intensity Factors (SIFs) for T-plate}

The SIFs for the bilinear distribution[3], the R6 and BS7910 distributions for T-plates are shown in Fig. 19(a). The figure shows that BS7910 is the most conservative, and R6, bilinear distribution and mean bilinear follow. In Fig. 19(b) the SIFs obtained using the data from the Grade S355 T-plate are compared with the three bilinear distributions. It may also be seen that the modified bilinear profile shown in Fig. 19(b) provides the best, conservative estimate of the SIFs for this geometry and material. Only the data for the Grade S355 material are shown for this comparison but similar conclusions can be made for the SE702 distribution. The bilinear distribution[3] tends to estimate the SIFs more conservatively as the crack length increases while the conservatism of modified bilinear remains approximately constant.

As shown in Fig. 19, the bilinear distribution[3] tends to estimate the SIFs conservatively. The linear bending stress profiles shown in Fig. 18(a) were used in the SIF analysis to compare with the experimental results for the Tplate. In Fig. 20 it is seen that the 'linear upper bound' linear distribution closely matches the result from R6. This is not surprising since for this geometry with $r_{0} / W=0.52$ the upper bound linear curve and the R6 curve are very similar. The linear distributions of $0.6 \sigma_{y}$ and $0.75 \sigma_{y}$ at the surface give good results over the whole range of crack lengths investigated. The $0.6 \sigma_{y}$ line gives conservative results except at very short crack lengths. Thus a recommendation of $0.75 \sigma_{y}$ surface stress would be safer for a linear distribution. However, as a whole the modified 
bilinear distribution provides the best representation of the SIFs for the T-plate geometries (compare Fig. 19(b) and Fig. 20).

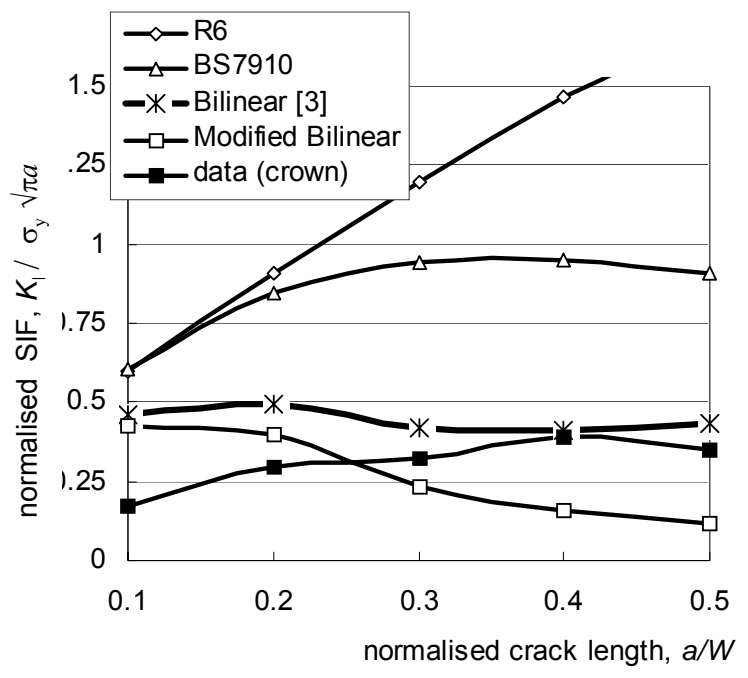

(a)

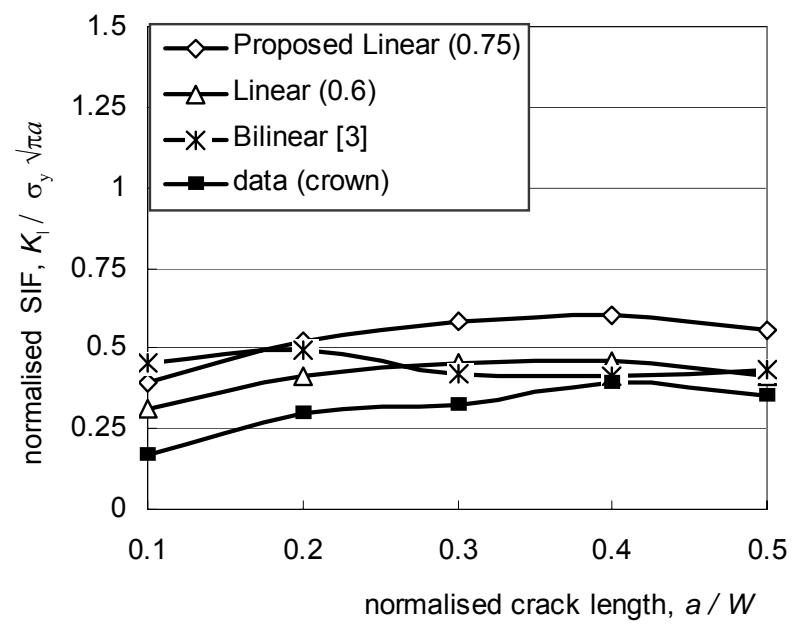

(b)

Fig. 21. The SIFs due to measured data and modified bilinear profile for tubular T (a) Current distributions (b) proposed linear profile

\subsection{Stress Intensity Factors (SIFs) for the Tubular T-joint}

The results for the SIFs obtained using the recommended distributions of R6, BS7910, bilinear[3] and the modified bilinear profile are shown in Fig. 21 (a) for the Tubular T-joint. The figure shows that the R6 distribution is the most conservative, and BS7910, bilinear and modified bilinear profile follow. Also included in the figure are the results obtained using the transverse stress data for the crown (where the stresses are highest). It is shown that the modified bilinear curve which showed good results for the T-plate underestimates the SIF for crack lengths $a / W<0.25$. Therefore, this modified bilinear profile could not be used for the tubular T-joint except for short cracks. However, the predictions from the original bilinear distribution from [3] show that the SIFs are close to the results for the measured data. This profile could be employed for a realistic assessment of the SIFs for tubular T-joint.

The results for the proposed linear distribution (see Fig. 18(a)) for the tubular T-joint are shown in Fig. 21(b). The linear distribution with yield strength $0.6 \sigma_{y}$ and $0.75 \sigma_{y}$ at the surface give conservative results over the full range of crack lengths (note that the bilinear distribution from [3] approaches quite closely to the prediction from the data at $a / W=0.4$ and thus the conservatism for this distribution is low. 
It was shown that the modified bilinear distribution provides the most realistic SIF values for the T-plate as shown in Fig. 19(b). However, this distribution tends to underestimate the SIFs over the crack lengths, $a / W>0.25$ for the tubular T-joint as shown in Fig. 21(a). As a promising comprehensive residual stress distribution, Fig. 21 shows that the proposed linear profile with a magnitude of $0.75 \sigma_{\mathrm{y}}$ at the surface can estimate the SIF values in both T-plate and tubular T-joint more reliably with less conservatism than the assessment procedures of R6 and BS7910.

\section{Conclusions}

In this paper, the recommended residual stress distributions in the British assessment procedure of R6 and BS7910 were reviewed for as-welded T-plate and tubular T-joints of two ferritic steels. In addition the profile from a recently proposed bi-linear solution[3] was also examined. All these have been derived from limited experimental measurement data which contain scatter due to different measurement and analysis techniques. In addition the measurements were not all performed on the same material and component size adding further to the variability of the data. Therefore it was concluded that detailed fits and profiles may not be necessary for every condition as there could be unexplained variabilites in the measured data. Hence a proposed simple route has been presented. Particular attention was paid to the stress intensity factors (SIFs) associated with these distributions and a comparison using a sensitivity analysis were performed on the different profiles in order to ascertain their level of conservatism.

The stress intensity factors under various types of loads were calculated using the Green's function method (GFM). A general method to determine the weight functions or Green's function in closed-form solution for a structure is not available. In this study the GFs were determined numerically over several locations on the crack surface and fitted to determine a GF at a specific crack length. The Green’s function approach has been developed for the T-plate and tubular T-joint which is simple to apply in determination of the SIFs, and the approach has been validated using closed form solution for single edge cracked plate and finite element analysis for T-plate and tubular T-joint. The present GFM enables one to determine the SIFs for the tubular T-joint with built-in end conditions which is statically indeterminate problem as well as for the T-plate which is statically determinate problem.

A simplified linear bending distribution covering the T-plate and tubular T-joint, derived from the mean and standard deviations of the available transverse residual stress data has been examined. A sensitivity analysis of the appropriate SIF calculations using the weight function method has been derived by varying the bending stress slope 
of the residual stress profile. It was shown that the simplified linear bending profile can provide an adequate residual stress distribution applicable for the range of geometries and materials examined to produce less conservative SIF values than what is presently available. In all cases it has been seen that that the SIF values are very sensitive to the bending component of residual stress and a small increase at the surface level of residual stress can have a profound effect on the SIF values.

\section{Acknowledgments}

The authors gratefully acknowledge help given by British Energy PLC, and Dr Noel O’Dowd and Professor G. A. Webster at Imperial College for helpful discussions and Dr Mark Daymond at ISIS for his assistance with the neutron diffraction measurements on the tubular T-joint. The Korean Ministry of Science and Technology that helped the participation of the first author is also gratefully acknowledged.

\section{References}

[1] British Energy Generation Ltd, Assessment of the Integrity of Structures Containing Defects, R6 Rev. 4. British Energy Generation Ltd, UK, 2001.

[2] British Standard Institution, Guide on methods for assessing the acceptability of flaws in metallic structures, BS7910: 1999 (Rev. March 2000) British Standards Institution, London, UK, 2000.

[3] Wimpory R., May P., O’Dowd N.P. Webster G., Smith D., and Kingston E. Measurement of residual stresses in T-Plate Weldments. Journal of Strain Analysis, 2003;38 (4): 3469-365.

[4] British Standard Institution, Hot rolled products of non-alloy structural steels - technical delivery conditions, BS EN 10025: 1993.

[5] British Standard Institution, Weldable structural steels for fixed offshore steels, BS 7191: 1989.

[6] Wang X., Lambert, S.B. On the calculation of stress intensity factors for surface cracks in welded pipe-plate and tubular joints. International Journal of Fatigue. 2003;25:89-96.

[7] Niu X, Glinka G. Weight functions for edge and surface semi-elliptical cracks in flat plates and plates with corners,” Engng Fracture Mech, 1990:36; 459-475.

[8] Wang X, Lambert SB, Weight functions and stress intensity factos for semi-elliptical cracks in T-plate welded joints. Fatigue Fracture Eng Mater Struc, 1998;21:99-117.

[9] May P. Effect of welding residual stresses on the fracture resistance of ductile steels, PhD Thesis : Imperial College London, 2002.

[10] O’Dowd NP., Nikbin KM., Lee H-Y., Wimpory R. and Biglari F. Stress Intensity Factors due to residual stresses in T-plate welds. Journal of Pressure Vessel Technology, Transactions of ASME, 2004;126(Nov):432438.

[11] Scaramangas A. and Porter Groff R. Residual stress in cylinder girth butt welds. 17th Offshore Technology 
Conference, OTC5024, 1985:25-30, May.

[12] Leggatt RH. Residual stresses at circumferential welds in pipes, The Welding Institute Research Bulletin. 1982;June:181-188.

[13] Leggatt R. Welding Residual stresses. International proceeding of the fifth international conference on residual stress, (ICRS-5), 1997:12-25.

[14] Hibbitt, Karlsson and Sorensen Ltd. ABAQUS, version 6.4. 2004.

[15] Wu X., Carlsson A., Weight functions and stress intensity factors solutions Pergamon Press, 1991.

[16] Lee H-Y, Nikbin KM, O’Dowd, NP. A generic approach for a linear elastic fracture mechanics analysis of components containing residual stress. 2005(82):797 806. 